\title{
Global pipelines and absorptive capacity: insights from the clustered firms at São Francisco River Valley
}

\section{Vinicius Farias Moreira*}

Federal University of Campina Grande, Aprígio Veloso, Street, 882 - Campina Grande-PB, Brazil

ORCID: https://orcid.org/0000-0002-4473-8766

Email: vinicius.moreira@ufcg.edu.br

${ }^{\star}$ Corresponding author

\section{Jose Luis Hervas-Oliver}

Universitat Politècnica de València, Campus vera s/n, 46022, Valencia, Spain and

Universidad de la Costa, Cl. 58 \#\#55 - 66, Barranquilla, Atlántico, Colombia ORCID: https://orcid.org/0000-0001-6438-5497

Email: jose.hervas@omp.upv.es

\author{
Adriana F. Chim-Miki \\ Federal University of Campina Grande, \\ Aprígio Veloso, Street, \\ 882 - Campina Grande-PB, Brazil \\ ORCID : http://orcid.org/0000-0001-7685-2718 \\ Email: adriana.c.miki@ufcg.edu.br
}

\section{Walter F. Araújo de Moraes}

Federal University of Pernambuco, Dezessete de Agosto Avenue, 892 - Recife, PE, Brazil ORCID: https://orcid.org/0000-0003-4582-0910 Email: wfam1950@gmail.com

\begin{abstract}
This study verified if the knowledge provides by global pipelines is absorbed by clustered firms contributes to minimising both local and clusters asymmetries. We studied one of the most important agricultural barns of Brazil, the fruit-growing cluster São Francisco River Valley (SFRV). It was a Case Study using the technique of Content Analysis through the ATLAS.ti software. A threefold data collection process enhanced the construct validity, allowing the triangulation of the sources and findings. The results showed that Global pipelines minimised the knowledge asymmetries among regions (macro level),
\end{abstract}


but increase the asymmetries inside the cluster, among the firms (micro level). There are two mediating variables to increase the cluster innovation, the firm absorptive capacity and the information access. In the empirical level, the results showed that manager consultants are an essential figure in the SFRV, they are innovation hunters from global markets and provided the knowledge transfer to clustered firms.

Keywords: fruit-growing cluster; global pipelines; absorptive capacity; asymmetries; knowledge transfer; innovation hunters; ATLAS.ti software.

Reference to this paper should be made as follows: Moreira, V.F., Hervas-Oliver, J.L., Chim-Miki, A.F. and de Moraes, W.F.A. (2019) 'Global pipelines and absorptive capacity: insights from the clustered firms at São Francisco River Valley’, Int. J. Knowledge-Based Development, Vol. 10, No. 4, pp.297-314.

Biographical notes: Vinicius Farias Moreira holds a $\mathrm{PhD}$ in Business Administration from the Federal University of Pernambuco, Brazil. He did a doctoral internship at the Polytechnic University of Valencia, Spain. Currently, he is an Associate Professor of Business in the graduate and postgraduate Program at Faculty of Management and Accounting at Federal University of Campina Grande, Brazil. Also, he is the research leader of the Business Competitiveness Research Group. Topics of his interest: business strategy, entrepreneurship, regional development, internationalisation, coopetition and competitiveness.

Jose Luis Hervas-Oliver holds a $\mathrm{PhD}$ in Business Organization from the Universitat Politècnica de València, Spain. Currently, he is a Full Professor of Innovation at Universitat Politècnica de València, (Spain). He is the principal research of Cluster Innovacion research group at the UPV. His research interests include cluster studies, strategic management; knowledge based-view and innovation.

Adriana F. Chim-Miki holds a PhD in Tourism, Economics, and Management from the University of Las Palmas de Gran Canaria, Spain. Currently, she is an Associate Professor of Business in the graduate and postgraduate Program at Faculty of Management and Accounting at Federal University of Campina Grande, Brazil. Also, she is the Leader of the Research Group Coopetition Network Lab. Topics of her interest: coopetition, competitiveness, interorganisational networks, strategic management, entrepreneurship, tourism and social management.

Walter F. Araújo de Moraes holds a PhD in Management Sciences from the University of Manchester Institute of Science and Technology, UMIST, UK, and a Post-doctorate in the University of Texas at Austin, USA. Currently, he is a consultant in the area of Business Strategy and a retired professor. His research interests include business strategy, internationalisation strategy, competition, competitive resources and business performance.

This paper is a revised and expanded version of a paper entitled 'Pipelines Globais e a Dinâmica da Criação de Valor de Empresas Geograficamente Concentradas' presented at XXXIX Encontro da ANPAD, Belo Horizonte, Brazil, 13-16 September, 2015. 


\section{Introduction}

Since Marshall (1920) geographic concentration is recognised as a success factor in business performance. However, Marshall's approach remained dormant until about the '1980s when the phenomenon began to receive more considerable attention from scholars of different fields of study (Meyer-Stamer, 2001). Among the studies that recover interest in the Industrial District concept, the approaches of Brusco (1982) and Pyke et al. (1990), among many others, tried to explain the socioeconomic anomalies of third Italy. These initial contributions provided the basis for the understanding the concept of agglomerations as a phenomenon in which companies within the same or related industry tend to congregate at the same region, providing the economies of location (Malmberg and Maskell, 2002) that provide a superior configuration of knowledge that may improve local firms' competitive advantage.

The relevance of the phenomenon has driven studies that analysed location advantages under different theoretical views, comprising contributions from economics, organisational and management, sociology, innovation, economic geography and regional studies and others (Albors-Garrigos et al., 2009; Fitjar and Huber, 2014; Henn, 2012; Lazzeretti et al., 2013; Martin and Sunley, 2003). However, despite being the literature on clusters very prolific, there is less research on the microeconomic level or the firm as a unit of analysis within clusters (Hervas-Oliver et al., 2018a). The existing literature, however, has unfolded a very interesting and emergent topic: cluster firm asymmetries, or how different firms can be within the same cluster (e.g., Belussi and Hervas-Oliver, 2018; Hervas-Oliver et al., 2017, 2018a, 2018b, 2019; Pinkse et al., 2018).

This emergent yet unsolved issue, related to the idea of firm heterogenity from strategy strand (e.g., Barney, 1991) indicates that the cluster effect is asymmetric and not all firms gain the same. In this study we seek to provide in-depth analysis of this question, adding a new feature that make the study novel and unique: the intersection of the cluster firm asymmetries and global value chains. All in all, the contribution of this study to the cluster literature is twofold. First, this paper contributes to enrich and disentangle cluster firm asymmetries. Second, the present study connects the global value chain approach (Bathelt et al., 2004; Belussi and Hervas-Oliver, 2018, 2017; Hervas-Oliver and Boix-Domenech, 2013) to the cluster firm asymmetries debate. To the best of our knowledge, this is the first study using both angles in an empirical case. We define cluster firm asymmetries as knowledge and performance differences among cluster firms due to their different configuration of resources and capabilities and absorptive capacity.

Cluster is a group geographically close of interconnected companies and associated institutions in a field, linked by shared and complementary interests (Porter, 1998). Inside the cluster, the interconnected companies would have additional advantages such as access to specialised suppliers, facilitated channels for clients, service providers, access to related industries and support of associated institutions (Giuliani, 2013; MolinaMorales and Martinez-Fernández, 2004; Porter, 1998).

Besides to these advantages, a new literature frontier showed that the dynamics of value creation by the clustered business is strengthened by external bonds of relationships, the global pipelines (Bathelt et al., 2004). However, it is a perspective still underexplored by scholars whose tends to focus on endogenous cluster perspective, as if the set of related industries and services in the cluster were self-sufficient (Henn, 2012; Hervas-Oliver and Albors-Garrigos, 2009). 
Global Pipelines provides access to different knowledge pools and prevent cluster formation becomes a technological trap (Bathelt et al., 2004; Giuliani, 2013; Henn, 2012; Morrison et al., 2013). Nevertheless, access to the knowledge derived from global pipelines depends on the firm absorptive capacity that assumes the role of the mediating variable between the company environment and the organisational adaptation (Bathelt et al., 2004).

The focus of scholars on the endogenous side of cluster left gaps to a whole understanding of its dynamics, especially by studying less cluster firm heterogeneity or asymmetries and the intersection of the external (global pipelines) and internal (cluster firm heterogeneity) sources of knowledge. In order to minimise this gap, our research investigated how the primary sources of global pipelines impact on the cluster asymmetries (macro and micro level) considering the absorptive capacity of firms. We address these issues by examining the dynamics of knowledge surrounding the Fruitgrowing Cluster São Francisco River Valley (SFRV), located between the provinces of Pernambuco and Bahia at Brazil, one of the essential agricultural barns in that country with proper insertion in international trade with mango and table grapes.

In order to achieve our objective, that is, deciphering whether and how knowledge by global pipelines is absorbed by clustered firms in the SFRV, focusing on how that external knowledge impacts on cluster firm knowledge asymmetries, our study is based on qualitative research. It tackles a Case Study based on the methodology of Content Analysis through the ATLAS.ti software. Our method uses three sources of data, in-deep interviews with clustered firms; in-deep interview with agents of support institutions; and analysis of documents and non-participant observation.

\section{Cluster resources and the global pipelines}

Based on the study of competitive advantage of nations, Porter (1990) proposed the Diamond Model with its four interrelated determinants which showed that success could be geographically located and, then he provided the basis to explain competitive industries clusters. In complement, theoretical contributions from the perspective of Internal Resources help organisational researchers to understand the influence of the territory on the firm's performance (Molina-Morales and Martinez-Fernández, 2004), even applying the resource-based view to the cluster-level (see Hervas-Oliver and Albors-Garrigos, 2007).

Analysis considering this viewpoint contribute to understanding the dynamics of value creation of clustered firms, because strategic resources cannot be understood without considering the influence of shared resources or the local resources. The argument is that the territories contain high-order capabilities, available to local firms and contribute to explaining the dynamics of internal resources. The interactions between the internal resources of the company and the local resources make possible a natural heterogeneity among them, given the context combines resources and capabilities (Hervás-Oliver and Albors-Garrigós, 2007).

The resources of the area are capabilities shared by clustered firms and, at the same time, they can represent sustainable competitive advantage, due to is difficult for external companies understand them. This type of resource comes from routines connected to the history of the companies, business practices, the specific institutions and multiple links between the players (Molina-Morales and Martinez-Fernández, 2004). This perspective 
also is supported by the knowledge based-view (KBV), which emphasises the interaction and exchange of information among the clustered companies and their capacity to create knowledge (Malmberg and Maskell, 2002; Tallman et al., 2004). Also, KBV considers the asymmetry in knowledge flows (Arikan, 2009; Tallman et al., 2004). On the one hand, the assimilation of the cluster knowledge by the clustered companies depends on the firm's absorptive capacity and its features that moderate the combination and accumulation process (Albors-Garrigos et al., 2009). On the basis of firm heterogeneity, we posit that cluster firm asymmetries occur because differences in firms' resources and capabilities or knowledge. As a result, local firms absorbe and exploit differently external knowledge (from the cluster) depending on their own internal capabilities. Therefore, as suggested by Hervas-Oliver et al. (2018a) or Pinkse et al. (2018), companies are exposed to similar external (to-the-firm) knowledge flows occurring in the location or cluster, however, each firm's performance differs from the rest, due to firm heterogeneity and its related different absorptive capacity of local and external (global pipeline) available knowledge.

\subsection{Dynamics of knowledge on the cluster atmosphere}

In this sense, Tallman et al. (2004) highlight that although component, in general, is transparent and mobile, not all knowledge moves among firms within (or beyond) a regional cluster the same rate. It means the individual capacity to learn and, transform knowledge in advantage limits the flow (Hervas-Oliver and Boix-Domenech, 2013). As a result, some firms do not acknowledge the benefits to be clustered (McCann and Folta, 2008).

Fitjar and Huber (2014) showed that inside the cluster, notwithstanding the density of local interactions, linkages do not seem to provide new knowledge or contribute to innovation. The intensity of global communications and the heterogeneous actors produce different learnings and skill levels. For these reasons, despite firms' geographic proximity, knowledge is diffused within clusters in a highly selective and uneven way (Giuliani, 2011).

Also, some scholars have stressed the potentially harmful effects of too much proximity (Ter Wal and Boschma, 2011) and over-embeddedness within clusters because it can conduct to a lock-in. The way to avoid it is through the creation and recombination of knowledge, internal and external (Morrison et al., 2013), i.e., the dynamics of value creation by clustered firms from external ties and flows (Hervas-Oliver and AlborsGarrigos, 2009; Hervas-Oliver and Boix-Domenech, 2013) that represent the global pipelines (Bathelt et al., 2004).

Innovation, knowledge creation and learning stem from the interactive process in which players with different skills work together to solve technical, organisational, commercial or intellectual problems (Aarstad et al., 2016; Fitjar and Huber, 2014; Henn, 2012). The results are changes involving both, interactions and learning within the cluster (local buzz) and, connections with external agents (global pipelines), so they make the companies open toward new knowledge and technologies, connecting them with the global value chains.

External ties are usually established from the participation of multinational companies in the global value chains (Gereffi et al., 2005) making the connections of knowledge among clusters (Hervas-Oliver and Boix-Domenech, 2013; Rigby and Brown, 2015). The ties with agents outside the cluster or foreign companies that work in various markets at 
the same time contribute to the transfer of knowledge and the reduction of territorial knowledge asymmetries (Hervas-Oliver and Albors-Garrigos, 2009). In regional clusters, they provide local-global connections, therefore became a crucial ingredient in the cumulative process of both firm and cluster development bring complementary assets (Iammarion, 2010).

Due to this interaction, stocks of knowledge are incorporated into the cluster atmosphere over time according to the both, firms and cluster absorptive capacity (Albors-Garrigos et al., 2009; McCann and Folta, 2008). The global pipelines include companies from different parts of the world, therefore embedded in various social, cultural and institutional contexts. The establishment of these links takes time and conscious efforts to avoid information failures. So, global pipelines are neither automatic nor free; they are resulting from specific investments, sometimes complex and costly process because requires institutional support and infrastructure and depend on the trust established among companies (Bathelt et al., 2004; Henn, 2012). Many times, these links are used by local institutions to promote partnerships that reduce research costs and provide expertise from interaction with external sources (Molina-Morales and MartinezFernández, 2004).

The search for international competitiveness leads clustered firms to develop strategic relationships with these 'non-local knowledge providers' that allow paths to achieve radical changes, internationalisation, global outsourcing, the knowledge offshore, etc. (Belussi and Sedita, 2009). Multinationals play a major role by transferring knowledge from cluster to cluster (e.g., Li and Bathelt, 2019), diffusing knowledge across locations and thus reshaping global value chains (e.g., Hervas-Oliver and Boix, 2013). Then, multinationals act as knowledge gatekeepers (e.g., Giuliani, 2011; Hervas-Oliver and Albors-Garrigos, 2014) by capturing and deciphering external (to the cluster) knowledge and diffusing within clusters. According to Henn (2012), the development of social networks represents one of the most critical located capabilities and, transnational entrepreneurs play an important role in external cluster relations. These global pipelines can influence positively or negatively the dynamics of regional clusters. On the one hand, transnational entrepreneurs can contribute to avoiding the Lock-in; on the other hand, they can weaken of traditional cluster structures due to induce relocations to low-cost economies (Fitjar and Huber, 2014; Malmberg and Maskell, 2006).

As indicated earlier, this research focuses on understanding how the primary sources of global pipelines impact on the cluster asymmetries (macro and micro level) considering the absorptive capacity of firms. We assume that Global Pipelines provides access to different knowledge pools (Hervas-Oliver and Albors-Garrigos, 2009; HervasOliver and Boix-Domenech, 2013), based on this, we defined four propositions, which are described below:

Proposition 1: Global pipelines reduce the asymmetries among regions or cluster at a macro level.

Proposition 2: Global pipelines tend to increase the asymmetries among firms, at the micro-level, due to cluster firm asymmetry or heterogeneity. 
Proposition 3: The external intermediary agents can minimise the asymmetries on the cluster atmosphere and the internal dissemination of knowledge.

Proposition 4: Global pipelines tend to produce gains of density of local interactions, new knowledge and innovation inside the cluster. That means, the proximity and overembeddedness within clusters did not conduct to a lock-in when the cluster has global pipelines.

\section{Methodologic design}

A qualitative case study approach was employed because this method allows describing a phenomenon since patterns in the data to develop conceptual categories that make it possible to illustrate, confirm or oppose theoretical assumptions (Patton, 2002). Even more, due to the limited knowledge about global pipelines, a case study method was necessary to explore and describe our research problem providing insights. The case was selected based on two main pre-defined criteria. Firstly, the cluster should be consolidated and vital to its regional territory, and second, the cluster must be an exporter to providing evidence of external networks.

The cluster of fruit producers and exporters located in the SFRV was selected because it is one of the essential agricultural barns in the country. Brazil is among the five largest mango exporters, with about $9 \%$ of world trade volume; and among the 15 largest grape exporters, with about $1.5 \%$ of the amount sold. According to the Ministry of Development, Industry and Foreign Trade of Brazil, the Cluster of SFRV accounted for about $90 \%$ of the exportation volume of these fruits.

We used multiple sources of data and methods to develop a comprehensive understanding and improve the reliability of results through triangulation of pieces of evidence (Villarreal Larrinaga, 2017). The threefold methodology consisted of documentary material, in-deep interviews, and non-participant observation. First, an assessment of the documentary material was conducted, including constitutive and informative documents of companies, associations, cooperatives, and support institutions. They allowed to complement the interview information, identify patterns of relationships and ways to create value for businesses and cluster.

Second, we conducted 13 semi-structured interviews of $1 \mathrm{~h}$ with executives from nine medium or large table grape and mango exporters from the SFRV, and others nine interviews were conducted with institutional and support industry actors. The interviews allowed analysing how horizontal relationship resources collaborated in the value creation process of fruit producing and exporting clustered firms at SFRV. Third, a nonparticipant observation was conducted by the researchers to confirm some pieces of evidence point out by the interviewees. Finally, the Content Analysis Technique was performed support by the Software ATLAS.ti provided reliability to theoretical-empirical interpretations, since it minimised the bias of personal interpretations.

According to Ang et al. (2016) qualitative researches are became more popularity based on two elements, the richness of collected data and, the advancement of CAQDAS (Computer Assisted Qualitative Data Analysis), because provides a systematic and rigorous analysis of qualitative data without risking trustworthiness but instead enhancing it (Carcary, 2011). We used the software ATLAS.ti to generate rigour and trustworthiness 
to a qualitative inquiry of the case study, at the same time, allow developed case study protocol based on a small number of respondents (Ang et al., 2016).

We selected a sample of 13 firms located at SFRV cluster that was, at the same time, in the list of exporting companies of the Ministry of Development, Industry and Foreign Trade and, in the list of register of grape and mangoes exporters of the Ministry of Agriculture. Regarding representatives of support institutions to the cluster were interviewed the nine local institutions of SFRV. The volume produced by the companies interviewed is over than $60 \%$ of the total cluster production, which reinforces the importance of the research findings.

The coding process was marked by comings and goings, as an iterative process that provided adjust the categories of analysis (Gioia et al., 2013). ATLAS.ti software enabled the systematisation of categories and subcategories, being illustrated through conceptual networks. The numbering that appears next to the quotations (excerpts encoded in the analysis), for example, QU: 15: 39 represents the 39th excerpt encoded in P-Doc 15; the Codes already show a numbering in brackets, for instance, $\{24-2\}$ indicating that the code was used 24 times and had 2 links with other codes. Occasionally the signal $(\sim)$ can be found, which represents the existence of a comment.

\section{Results}

The sub-middle region of the São Francisco Valley is an area of 360 hectares of irrigable where 120,000 hectares used to the cultivation of fruits, vegetables and sugarcane. It's located at $365 \mathrm{~m}$ of altitude with semi-arid tropical climate has an average temperature about $26^{\circ} \mathrm{C}$, an average relative humidity of $50 \%$, average annual rainfall of $450 \mathrm{~mm}$ and about $3000 \mathrm{~h}$ of sunshine per year. The region generates approximately 240,000 direct jobs and 960,000 indirect. Analysis of interviews with support institutions and governmental organisations showed that they recognise the fruit-growing Cluster of SFRV as a viable economic option to local development.

Analysis of documents and non-participant observation showed that this region has an adverse condition of drought and poverty. However, the political will, the support of local institutions and the business community capacity led the area of sub-middle SFRV to overcome this context and, they became one of the chief granaries of fresh fruit in the country with a high level of internationalisation.

"Fruit growing activity stands out for generating jobs, income and regional development. Although it does not represent an economic activity in the large Brazilian economic scale for export, the fruit production emerges with an important social role, job creation in remote areas with low industrialisation rates.” (Brazilian Micro and Small Business Support Service_Interviewed 5:20)

Documentary analysis showed that Fruit-growing Cluster SFRV included numerous small producers, with about 1-10 hectares and large producers, with more than 50 hectares, some passing 200. However, as confirmed by the interviewees there is no statistical data about the total of producers.

"There is not a sense of the number of producers in the São Francisco River Valley, but it is estimated that there is about 2,500 spread over the irrigation projects and around them.” (Development Company of São Francisco and Parnaíba River Valley_Interviewed 7:51) 
Besides, based on the interviews, we verified that usually, some players buy fruits of small producers to attend the demand by the global market. That practice generates dependence of supplier, but also, favours the information flow along the productive chain to ensure products and process according to the international standard. On the other hand, in the domestic market, the producers at the SFRV generally conduct their commercial practices directly, being a competitive advantage primarily related to lesser differentiated fruits.

The results showed SFRV cluster maintain exportation channels with essential markets, and it is in compassing with the Brazilian agribusiness (with emphasis on the grape and mango). Also, it demonstrated progress in the professionalisation of the national fruit production, gaining scale and quality to compete in American, European, Asian and the Middle East markets. In recent years, business enterprises have advanced in the production of wines, in the agroindustry producing juices and concentrates of tropical fruits (mango, acerola, passion fruit, pineapple, and cashew), among other related activities. The business report indicated that one of the largest region producers could process more than 120 tons of fruit per day at the Petrolina Agroindustry Unit (Firm_Secondarydata 16:22).

\subsection{Identifying the global pipelines of fruit-growing cluster SFRV}

The region of SFRV suffers long periods of dry, and thanks to a knowledge derivate by global pipelines; they implement a solution using the irrigation process. The interviews showed that external bonds were from institutional action, as predicted by MolinaMorales and Martinez-Fernandez (2004), that started since the design phase of economic activity at SFRV. For instance, the reported by the communications officer at CODEVASF (Development Company of São Francisco and Parnaíba River Valley).

"Codevasf sought to develop an irrigation project model compatible with the systems operating in Israel and Mexico, received technical support professionals from these countries and passed on the operational management to the shareholders of the system.” (Codevasf_Interviewer 1: 3)

The data collection analysis confirmed that the evolution of Fruit-growing Cluster SFRV had institutional support also to promote the development of products with more addedvalue. Two examples extracted from interviewees' comments were the wine industry and seedless grape growing.

"Codevasf brought experts from Europe to make this treatment [seedless grape], paid consultants, we had an agreement of technical cooperation with Hungary, the consultants have done work on the seedless grape that became a reality here.” (Codevasf_Interviewed 1:12)

The seedless grape cultivation represented an innovation in the region and became a driver for the expansion of export activities due to its differentiation and added value. In a theoretical lens, this represents the 'non- local knowledge providers' that allow, among other benefits, paths to the introduction of radical changes (Belussi and Sedita, 2009).

The data analysis of SFRV identified global pipelines in many ways and its effects generated by the absorptive capacity of the firms and cluster (Figure 1). For instance, knowledge exchange with others national and international clusters; technical knowledge links with external sources; research and development of new varieties; alliance with foreign firms to sell in the global market; institutional support; knowledge exchange 
through international auditing on the farms; commercial partnerships to import fruit in the phases of the offseason; participation in international fairs and field days; and, partnerships with credit insurers. It was also noticed that consultants in the region provided many of these external links.

Figure 1 Global pipeline at fruit-growing cluster SFRV (see online version for colours)

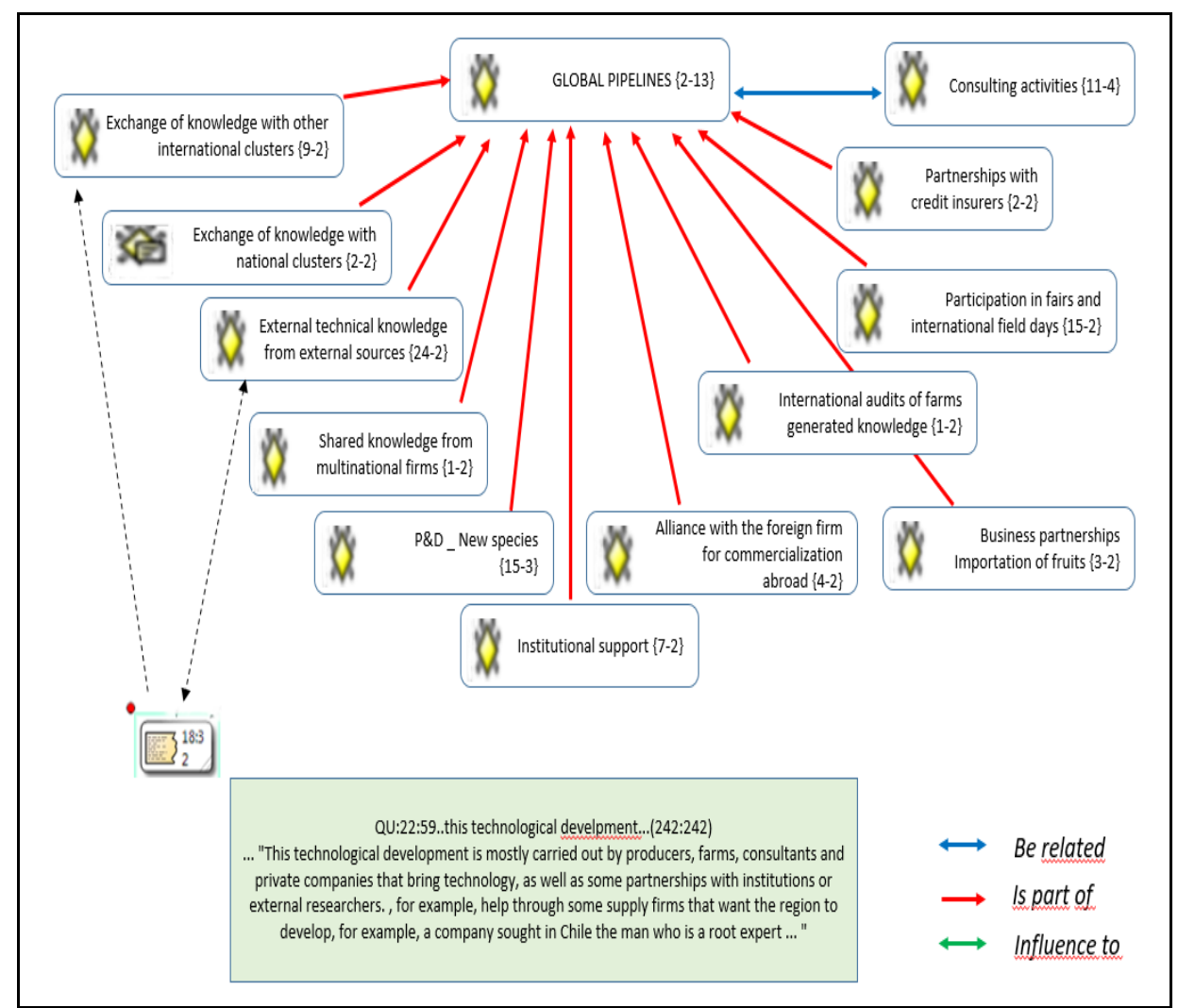

Source: Elaborated by the authors since ATLAS.ti results

The results of Content Analysis pointed out global pipelines include companies embedded in different social, cultural and institutional contexts. Also, the pipelines demand a complex and costly process, requiring institutional support and infrastructure, as indicated by Bathelt et al. (2004). Global pipelines of SFRV were intermediated by local institutions promoting partnerships to reduce research costs and providing expertise gains from interaction with external sources.

The new knowledge, absorbed by clustered firms at SFRV, led to companies invested in varieties that are more resistant to weather conditions. Thus, varieties initially introduced in 2001 and 2002 are being replaced by new types, more fertile, coming from other breeding companies around the world. Global pipelines effects go beyond the firm's advantage, became a regional competitive advantage. 
"The use of new varieties seeks less dependence on labour (the main ingredient of the production cost), increased shelf life of durability, strength, flavour, colour, berry size, brix, finally, features that ensure greater competitiveness.” (Brazilian Micro and Small Business Support Service - Interviewer 6:16)

The firms at fruit-growing cluster SFRV overcome the national knowledge thank their absorptive capacity. For instance, in Brazil, EMBRAPA (Brazilian Agricultural Research Corporation) launched two varieties of seedless grapes, Vitoria and Isis; however, they did not reach the international quality standards yet. Nevertheless, some firms in the SFRV through external knowledge achieved success in the global markets of seedless grapes.

\begin{abstract}
"Regarding grapes, the varieties that we export are derived from investment of producers and agricultural input stores that send consultants or senior officials of these companies to other countries in search of new varieties, and then bring forth and do the experiments." (Valexport_Interviewed 7:15)
\end{abstract}

Indeed, as demonstrated by the Content Analysis that produced a coding scheme graph in a network view (Figure 1), the consultants in São Francisco Valley represent an essential link between the farms and technological development, a path to bring new knowledge. Many interviewees report this link.

\begin{abstract}
"When multinational pesticide companies, for example, want to join with its revolutionary product, which increases the production or the size of grapes, usually it enters the cluster through consultants. Other times, multinational support brings foreign experts with relevant knowledge that affect productivity, like root experts from Chile. These consultants are testing in a private area, they choose some farms then share the information between the units they assist.” (Firm_Interviewed 22:60)
\end{abstract}

Some consultants were interviewed to confirm them as global pipelines and understand the generation of absorptive capacity in the clustered firms at SFRV. It was verified that the consultants seek to bring relevant knowledge related to fruit productivity in other parts of the world, analysing what can be merged into the reality of SFRV, and, thus, they offer that knowledge to the firms.

"I follow all this market, travel to producing countries to meet the competitiveness ways and bring here.” (GrapesConsultant_Interviewed 3: 8)

Global Pipelines related to research and development were identified in research data, illustrating the participation of SFRV companies at the global value chain of fruit. As noted by Gereffi et al. (2005) and, Humphrey (2006) external ties are usually established from the participation of multinational companies in the global value chains. Thus, in the fruit-growing cluster SFRV, among the companies surveyed, there is the case of Labrunier which maintains one of the most significant experimental areas of new types of grapes around the world.

Likewise, the partnerships with national research centers (EMBRAPA) and international (IFG, SNFL, Giumarra, Stargrow and Aat Hoekstra) seek continuous improvement in its production. "We're in an area of 4.8 hectares with 85 varieties being tested" (Firm_ Interviewed 13:12). Another interviewed from one of the largest fruit producer group in the world, indicate that the region of SFRV already has the presence of genetic improvements multinationals, like Sunworld. 
"They (multinationals of genetic improvements) access businesses through consultants, agronomists and/or production executives to recommend the choice of new varieties to ensure increased productivity and financial gains. In the case of Sunworld, the seedlings come from South Africa, are submitted to tests then proceed to commercial production.” (Firm_Interviewed 31:25)

Data collected indicated that some of these new varieties are unique to one specific farm, other types are explored by a limited number of producers, and another may be sold openly to all interested parties, which will pay royalties on sales. Thus, it confirms the theoretical lens that the value creation depends on the absorptive capacity of firms (Tallman et al., 2004), i.e., is not 'free' in space but limited by the ability that each company must learn and transform knowledge into a competitive advantage (Hervas-Oliver and Boix-Domenech, 2013). Therefore, the low absorptive capacity of some firms causes a lack of acknowledges advantages to be clustered (McCann and Folta, 2008).

One of the varieties well accepted among grape growers is the Arra-15, which belongs to Agricultural Research for Development, a subsidiary of Giumarra Vineyards Corporation, California. During his interview, the president of Small producers highlights that the farmers resist acquiring the rights to explore the recommended varieties.

The reported confirmed the logic of stocks of specific knowledge protect by asymmetries in the knowledge flows and the dynamics of a cluster and its surrounds (Arikan, 2009; Tallman et al., 2004). Also, the results support the approach of HervasOliver and Albors-Garrigos (2009) on agents outside the cluster, that are in various geographical regions at the same time, reduce knowledge asymmetries among territories. The theoretical lens of Hervas-Oliver et al. (2009) was focused on minimising differences of knowledge among clusters or areas, that is, the macro level of asymmetries, however, there are asymmetries in the micro level, i.e., inside the cluster.

From the analysis of Case of SFRV emerged another type of asymmetry at a micro level of the cluster. Both are hindering the absorptive capacity of clustered companies, firm's abilities and free access to the value created. The literature points out individual absorptive capacity as a mediator variable between the environment and organisation adaptation (Bathelt et al., 2004). Nevertheless, we analysis indicated that free access to new value created inside the cluster is another mediator variable that plays an active role in the innovation process and competitive advantage to the clustered firms.

It is also interesting to record that the choice of new varieties requires adjustment to the internal resources of the company, reinforcing the view that the absorptive capacity of each company will be moderated by combining their resources and knowledge accumulation process (Hervás-Oliver and Albors-Garrigós, 2007).

\footnotetext{
"We ended up bringing seedless grapes in several varieties, from various regions of the world, we grew it here, then we identify the varieties that had more potential to be produced in our climate and soil conditions; as the varieties were identified we kept modifying agricultural practices with that range until we reached success and productivity that we have today with these varieties.” (Firm_Interviewed 15:39)
}

Companies with exclusivity in varieties also participated in this case study. An export company of mango have exclusivity in the SFRV on a variety of mango originated from Westfalia, a company in South Africa. The entrepreneur had contact with Westfalia group through European partner, which already worked with an avocado producer in São Paulo 
to test Honey Gold mango variety but did not work due to São Paulo conditions. Thus, they decided to test at the SFRV.

"I asked him to send me there from São Paulo, and he sent two hundred plants and I grafted here and multiplied by two hundred more. So, in fact, we tested a variety that had first arrived in São Paulo and brought to the reality of Pernambuco.” (Firm_ Interviewed 18:48)

In this case, it is possible to visualise the networking power to recombine knowledge, confirming Malmberg and Maskell (2006) indicated the development of social networks represent one of the most critical located capabilities. From the interviewees' comments and documental analysis, participation in international fairs and stories about participation in technical visits overseas were also recognised as relevant sources of external bonds. Entrepreneurs and institutions pointed to Fruit Logistica, which takes place once a year in Berlin (Germany), as the primary source of access to international customers, and access to inputs and exchange of information of various kinds.

\begin{abstract}
"Some companies even put their own stand to present their products; others participate through the support Brazilian Fruit Institute (Instituto Brasileiro de Frutas, IBRAF) and the Brazilian Agency for Export and Investment Promotion (Agência Brasileira de Promoção de Exportações e Investimentos, ApexBrazil). And, others just to keep tuned to the market, present the plans for next season and know the feedback on our performance (SFRV Cluster) in the previous season.” (Firm_SecundaryData 1:1)

"The good development in Africa also brought greater security to investments in Brazil. These are opportunities for knowledge exchange about the variety, involving especially cultivation and marketing.” (Firm_Interviewed 13:28)
\end{abstract}

Global pipelines of SFRV also acts on knowledge capacity absorptive of the firm to commercial partnerships to import fruits to the market during the off-season, as could verify by the interviews.

"So, if we're out of grape, we search a market that has it. We did this to supply
the need of the client, and not give space for productors from Argentines,
Chileans and Peruvians get in our market. "(Firm_Interviewed 13: 9)

The non-participant observation confirmed that external sources provide an upgrade of technological capability thanks to the firm's absorptive capacity. We observed that new technologies from abroad to optimise the production was implanted in the farms. For instance, the workforce is one of the most high-cost components of production, thus, the use of machines to pack the grapes automatically using bowls of a fixed weight, reduced the handling, thus improve the quality of the fruit and increase sector's competitiveness.

Another tech innovation in the SFRV was purchased electronic reader, which distinguishes up to two shades of the same colour and two electronic scales, thus it promotes standardisation of batches according to customer demand. In the production phase, the technology came as an electrostatic spray, able to reduce water use in the vineyard and optimise the application of agrochemicals.

A global pipeline is a double-way. This case analysis showed that SFRV knowledge has also been taken to other regions of the World, especially to Peru, according to interviews. It was reported that several technicians, agronomists and consultants with extensive experience went there because the similar weather to Brazil allows the grape production. 


\begin{abstract}
"Peruvians could not be based on a technology from Chile, which is a temperate climate, nor South Africa or California. As the weather is very similar, they rely heavily on technology we developed here in the SFRV. So, this exchange is very strong. They come much over here, we will not really go there because they are at the stage of learning, right?” (Firm_Interviewed 22:43)
\end{abstract}

The data analysis illustrates that knowledge is circulating inside the cluster (micro level) and outside the cluster (macro level) and, little-to-little it is absorbed by firms to become a value creation to both, companies and cluster. Finally, it was noticed in the SFRV that external ties established by the various players within the cluster strengthen and complement the process of creating strategic value, these connections enable the achievement of global excellence supplies and reduce knowledge asymmetries between different producing regions.

\title{
5 Conclusions
}

This paper has sought to substantiate the theoretical lens on cluster studies by external bonds of relationships, so an exogenous perspective on clusters resources. The study investigated how the primary sources of global pipelines impact on the cluster asymmetries (macro and micro level) considering the absorptive capacity of firms. In sum, our findings provided four main approaches to the literature and three empirical contributions to the managers in the fruit-growing cluster.

According to our Proposition 1 in a macro level, Global pipelines reduce the asymmetries among regions or cluster, however in a micro level, that is, inside the cluster, the global pipelines tend to increase the asymmetries among firms. In the SFRV was perceived that the establishment of external ties enables innovation and reduction in knowledge asymmetries along the global supply chain (macro level), that happens in different ways.

These external sources feeding the dynamics of knowledge in-out-side (out-in-side) the cluster, due to the SFRV showed to be a link to bring knowledge from developed markets at the same time to be a diffuser of expertise to other clusters in Latin American. For instance, to Peru, as reported in the interviews of the SFRV Cluster. Thus, the results confirmed the advances concerning the mainstream of the area related to connections to global value chains, recognising that the cluster is not self-sufficient in creating new knowledge and this interaction reduces the distance from the major global competitors. Therefore, global pipelines contribute to reducing cluster-level (macro) asymmetries. Thus, Proposition 1 is validated. This inter-cluster asymmetries reduction confirms the existing literature on the role that multinationals and their associated global knowledge pipelines transferring knowledge from cluster to cluster (e.g., Hervas-Oliver and Boix, 2013; Li and Bathelt, 2018; Belussi and Hervas-Oliver, 2018).

At the micro level, however, the findings pointed to evidence that different levels of clustered firm's absorptive capacity may be associated with the structural market arrangements. The size of some companies, for example, has conditioned the reach of technological innovations via global pipelines increasing the knowledge asymmetries within the cluster (micro level), at least in an initial phase of the bet technological. Thus, as regards the Proposition 2 on cluster firm asymmetry, the proposition is validated, 
contributing to and confirming emergent literature on cluster firm asymmetries (e.g., Hervas-Oliver et al., 2018a; Pinkse et al., 2018).

A third novel contribution was related to the stated Proposition 3. It is the identification of a new element enhancing global pipelines and their effects in clusters: the role of intermediaries or consultants among knowledge and value creation. As indicated in Proposition 1, literature indicated that external ties are usually established from the participation of multinational companies in the global value chains (Gereffi et al., 2005; Hervas-Oliver and Boix-Domenech, 2013; Rigby and Brown, 2015). As well as, through the social networks of the clustered members (Malmberg and Maskell, 2006), and transnational entrepreneurs (Henn, 2012). However, the data analysis in SFRV showed the strong presence of consultants, that acts like innovation hunters in the market, being an intermediary way among the external knowledge and its absorption by the firms. At the same time, they influence the cluster atmosphere over time when they transpose the knowledge firm-to-firm to contributing to value creation inside the cluster. Multiple relations between producers took it upon themselves to disseminate new knowledge in the locality. These results resemble the role of technology gatekeepers (Hervas-Oliver and Albors-Garrigos, 2014; Giuliani, 2011), in charge with diffusing technology within the cluster. In particular, our contribution in this part connects the role of technology gatekeepers, accessing external knowledge and diffusing it within the cluster firms, to the cluster firm asymmetries, linking these two yet unrelated concepts. The results validated Proposition 3.

Thus, our Proposition 4 questions the statements regarding the relation between local density and lock-in, suggesting thus a different point of view. Indeed, the findings in the SFRV showed that through a global pipeline the knowledge passed from productor-toproductor due, to the density and interactions among them resulting in innovations that avoid the Lock-in. Therefore, the results validated Proposition 4, confirming cluster literature (e.g., Hervas-Oliver and Albors-Garrigos, 2014), pointing out that high density and low distance is better for knowledge diffusion (e.g., Brusco, 1982; Belussi and Hervas-Oliver, 2017, 2018). The external ties make the cluster closer to other markets successful. However, it was the density of small producers, and strong relationships among them provide by interorganiSational arrangements like cooperatives which provide the dissemination of knowledge into the cluster atmosphere. Multiple relations between producers took it upon themselves to spread new knowledge in the SFRV cluster. Thus, global pipelines in clusters with a high density of firms break the general similarity among companies regarding the stock of knowledge.

As empirical contributions to fruit-growing cluster SFRV, this study offers highlight twofold findings. The global pipelines are generating internal asymmetries among the firms and, producers most of them caused by the non-free knowledge, in hand of few. This situation can be a danger to maintain the cluster structure, due to hinder the absorptive capacity and generates a lack of acknowledges advantages to be clustered as explained by McCann and Folta (2008). Institutions of support were fundamental players to provide a bridge to flow external knowledge pass through SFRV Cluster, and reduce de asymmetries at the micro level. Even more, some cases themselves represent global pipelines.

Our empirical results have implications for the management and policies of clusters. They allow understanding the phenomenon in order to act toward to avoid unwanted effects caused by global pipelines. From our finding we can infer that the cluster management should be the focus on three points: 
1 to incentive the presence of external intermediary agents

2 to establish a policy to avoid the blockade of knowledge flows

3 to create a cluster atmosphere based on proximity and social ties.

According to our results, we conclude that clustered firms in the SFRV absorb the knowledge generated by global pipelines; however, the absorption rate is asymmetric or unequal along the cluster, thus occurs reduction of asymmetries among regions or countries, even among another cluster, that is, macro level. Nevertheless, global pipelines in the SFRV have increased the asymmetries at the micro level, at least in a short-term.

Finally, this study had limitations. One of them was the sample size. More interviews could provide extra-information, despite the method used considers the saturation level in the reported by participants. Another limitation was the access to information in some clustered companies.

As paths for future studies are suggested: analysis to measure the absorption of knowledge levels brought by the global pipelines between the cluster companies, which would allow the understanding of absorption asymmetries; make comparative study other in-nature fruit clusters along the world and/or clusters of different sectors; and, analyse how small businesses benefit from the knowledge generated by the External Ties or global pipelines.

\section{Acknowledgement}

We thank CAPES Foundation of Brazilian Ministry of Education for the support financial to the research through a $\mathrm{PhD}$ scholarship and, the Brazilian Council for Scientific and Technological Development (CNPq) by the Universal Call 01/2016 (process 431471/2016-9). We also thank the Spanish Ministry of Science, Innovation and Universities for the Research Project on innovation in clusters (RTI2018-095739-B-100), where Dr. Hervas-Oliver serves as Principal Researcher.

\section{References}

Aarstad, J., Kvitastein, O.A. and Jakobsen, S-E. (2016) 'Local buzz, global pipelines, or simply too much buzz? A critical study’, Geoforum, Vol. 75, pp.129-133.

Albors-Garrigos, J., Hervas-Oliver, J.L. and Hidalgo, A. (2009) 'Analysing high technology adoption and impact within public supported high tech programs: an empirical case', The Journal of High Technology Management Research, Vol. 20, No. 2, pp.153-168.

Ang, C.K., Embi, M.A., and Md Yunus, M. (2016) 'Enhancing the quality of the findings of a longitudinal case study: reviewing trustworthiness via ATLAS.ti', The Qualitative Report, Vol. 21, No. 10, pp.1855-1867.

Arikan, A.T.. (2009) 'Interfirm knowledge exchanges and the knowledge creation capability of clusters', Academy of Management Review, Vol. 34, No. 4, pp.658-676.

Barney, J. (1991) 'Firm resources and sustained competitive advantage', Journal of Management, Vol. 17, No. 1, pp.99-120.

Bathelt, H., Malmberg, A., and Maskell, P. (2004) 'Clusters and knowledge: local buzz, global pipelines and the process of knowledge creation’, Progress in Human Geography, Vol. 28, No. 1, pp.31-56. 
Belussi, F., and Hervas-Oliver, J.L.. (2017) Unfolding Cluster Evolution, Routledge, Ed., Routledge, New York.

Belussi, F. and Hervas-Oliver, J.L. (Eds.) (2018) Agglomeration and Firm Performance, Springer, Berlin.

Belussi, F. and Sedita, S.R.. (2009) 'Life cycle vs. multiple path dependency in industrial districts', European Planning Studies, Vol. 17, No. 4, pp.505-528.

Brusco, S. (1982) 'The emilian model: productive decentralisation and social integration', Cambridge Journal of Economics, Vol. 6, No. 2, pp.167-184.

Fitjar, R.D. and Huber, F. (2014) 'Global pipelines for innovation: insights from the case of norway', Journal of Economic Geography, Vol. 15, No. 3, pp.561-583.

Gereffi, G., Humphrey, J. and Sturgeon, T. (2005) 'The governance of global value chains', Review of International Political Economy, Vol. 12, No. 1, pp.78-104.

Gioia, D.A., Corley, K.G. and Hamilton, A.L.. (2013) 'Seeking qualitative rigor in inductive research: notes on the gioia methodology', Organizational Research Methods, Vol. 16, No. 1, pp.15-31.

Giuliani, E. (2011) 'Role of technological gatekeepers in the growth of industrial clusters: evidence from chile’, Regional Studies, Vol. 45, No. 10, pp.1329-1348.

Giuliani, E. (2013) 'Network dynamics in regional clusters: evidence from chile’, Research Policy, Vol. 42, No. 8, pp.1406-1419.

Henn, S. (2012) 'Transnational entrepreneurs, global pipelines and shifting production patterns: the example of the palanpuris in the diamond sector', in', The Global Diamond Industry (pp.87115) Springer.

Hervas-Oliver, J.L. and Albors-Garrigos, J. (2014) 'Are technology gatekeepers renewing clusters? Understanding gatekeepers and their dynamics across cluster life cycles’, Entrepreneurship and Regional Development, Vol. 26, Nos. 5-6, pp.431-452.

Hervas-Oliver, J-L. and Albors-Garrigos, J. (2009) 'The role of the firm's internal and relational capabilities in clusters: when distance and embeddedness are not enough to explain innovation. Journal of Economic Geography, Vol. 9, No. 2, pp.263-283.

Hervas-Oliver, J-L. and Boix-Domenech, R. (2013) 'The economic geography of the meso-global spaces: integrating multinationals and clusters at the local--global level', European Planning Studies, Vol. 21, No. 7, pp.1064-1080.

Hervas-Oliver, J-L., Lleo, M. and Cervello, R. (2017) 'The dynamics of cluster entrepreneurship: knowledge legacy from parents or agglomeration effects? The case of the castellon ceramic tile district', Research Policy, Vol. 46, No. 1, pp.73-92.

Hervas-Oliver, J.L., Sempere-Ripoll, F., Rojas Alvarado, R. and Estelles-Miguel, S. (2018a) 'Agglomerations and firm performance: who benefits and how much?', Regional Studies, Vol. 52, No. 3, pp.338-349.

Hervas-Oliver, J-L., Albors-Garrigos, J., Estelles-Miguel, S. and Boronat-Moll, C. (2018b) 'Radical innovation in marshallian industrial districts', Regional Studies, Vol. 52, No. 10, pp.1388-1397.

Hervas-Oliver, J-L., Sempere-Ripoll, F., Estelles-Miguel, S. and Rojas-Alvarado, R. (2019) 'Radical vs incremental innovation in marshallian industrial districts in the valencian region: what prevails?’, European Planning Studies, Vol. 4313, pp.1-16.

Hervas-Oliver, J-L. and Albors-Garrigos, J. (2007) 'Do clusters capabilities matter? An empirical application of the resource-based view in clusters', Entrepreneurship and Regional Development, Vol. 19, No. 2, pp.113-136.

Iammarion, S. (2010) 'The relationship between multinational firms and innovative clusters', Handbook on Evolutionary Economic Geography, Vol. 1, pp.182-204.

Lazzeretti, L., Sedita, S.R. and Caloffi, A. (2013) 'Founders and disseminators of cluster research', Journal of Economic Geography, Vol. 14, No. 1, pp.21-43. 
Li, P. and Bathelt, H. (2019) 'Headquarters-subsidiary knowledge strategies at the cluster level', Global Strategy Journal, in press, https.//doi. org/10.1002/gsj.1356

Malmberg, A. and Maskell, P. (2002) 'The elusive concept of localization economies: towards a knowledge-based theory of spatial clustering', Environment and Planning A, Vol. 34, No. 3, pp.429-449.

Malmberg, A. and Maskell, P. (2006) 'Localized learning revisited’, Growth and Change, Vol. 37, No. 1, pp.1-18.

Marshall, A.. (1920) Principles of Economics: An Introductory Volume, 8th ed., The Macmillan Press, 1st ed., published 1890.

Martin, R. and Sunley, P. (2003) 'Deconstructing clusters: chaotic concept or policy panacea?', Journal of Economic Geography, Vol. 3, No. 1, pp.5-35.

McCann, B.T. and Folta, T.B.. (2008) 'Location matters: where we have been and where we might go in agglomeration research', Journal of Management, Vol. 34, No. 3, pp.532-565.

Meyer-Stamer, J. (2001) Estratégias De Desenvolvimento Local e Regional: Clusters, Política De Localização e Competitividade sistêmica, Friedrich-Ebert-Stiftung.

Molina-Morales, F.X. and Martinez-Fernández, M.T.. (2004) 'Factors that identify industrial districts: an application in spanish manufacturing firms', Environment and Planning A, Vol. 36, No. 1, pp.111-126.

Morrison, A., Rabellotti, R. and Zirulia, L. (2013) 'When do global pipelines enhance the diffusion of knowledge in clusters?', Economic Geography, Vol. 89, No. 1, pp.77-96.

Patton, M.Q. (2002) 'Two decades of developments in qualitative inquiry: a personal, experiential perspective', Qualitative Social Work, Vol. 1, No. 3, pp.261-283.

Pinkse, J., Vernay, A-L. and D’Ippolito, B. (2018) 'An organisational perspective on the cluster paradox: exploring how members of a cluster manage the tension between continuity and renewal', Research Policy, Vol. 47, No. 3, pp.674-685.

Porter, M. (1990) 'The competitive advantage of nations', Harvard Business Review, Vol. 68, No. 2, pp.73-93.

Porter, Michel. (1998) 'Clusters and the new economics competition', Harvard Business Review, Vol. 76, No. 6, pp.77-90.

Pyke, F., Becattini, G. and Sengenberger, W. (1990) Industrial Districts and Inter-Firm CoOperation in italy, International Institute for Labour Studies.

Rigby, D.L. and Brown, W.M.. (2015) 'Who benefits from agglomeration?', Regional Studies, Vol. 49, No. 1, pp.28-43.

Tallman, S., Jenkins, M., Henry, N. and Pinch, S. (2004) 'Knowledge, clusters, and competitive advantage’, Academy of Management Review, Vol. 29, No. 2, pp.258-271.

Ter Wal, A.L.J. and Boschma, R. (2011) 'Co-evolution of firms, industries and networks in space', Regional Studies, Vol. 45, No. 7, pp.919-933.

Villarreal Larrinaga, O.. (2017) 'Is it desirable, necessary and possible to perform research using case studies?’, Cuadernos De Gestión, Vol. 17, No. 1, pp.147-172. 